\title{
NATURAL BIOMATERIALS FOR SKIN TISSUE ENGINEERING: REPAIR AND REGENERATION - A SHORT REVIEW
}

\author{
GOWRISANKAR L ${ }^{1 *}$, GANESH MURALI J ${ }^{2}$, USHA P ${ }^{3}$ \\ ${ }^{1}$ Department of Chemistry, Karpagam College of Engineering, Coimbatore - 641 032, Tamil Nadu, India, India. ${ }^{2}$ Department of Mechanical \\ Engineering, Karpagam College of Engineering, Coimbatore - 641 032, Tamil Nadu, India. ${ }^{3}$ Department of Science and Humanities, Faculty \\ of Engineering, Karpagam Academy of Higher Education, Coimbatore, India. Email: gowrishankar.l@kce.ac.in
}

Received: 02 April 2018, Revised and Accepted: 02 June 2018

\section{ABSTRACT}

The development of new materials and the enhancement of existing materials to develop skin regeneration are wide areas of research in polymeric biomaterials. The paper presents the analysis of a wide range of several natural polymers such as proteins and polysaccharides which can be utilized for skin tissue repair and regeneration. The reviews look at the few examples of commercially available natural - origin polymers with applications in tissue engineering. Natural polymers, such as proteins and polysaccharides, being components of, or structurally similar to, the glycosaminoglycans in the extracellular matrix (ECM) are valuable materials for tissue engineering applications. Natural polymers have great coincidence to natural ECM elements, particularly in biocompatibility and biodegradability. In this paper, the attention is focused on several natural polymers that found application in research work for drug or cell delivery within the skin tissue engineering field, namely collagen, chitin, chitosan, alginate, gellan, gelatin, and curcumin.

Keywords: Skin tissue engineering, Extracellular matrix, Regeneration, Biomolecules, Drug delivery.

(C) 2018 The Authors. Published by Innovare Academic Sciences Pvt Ltd. This is an open access article under the CC BY license (http://creativecommons. org/licenses/by/4. 0/) DOI: http://dx.doi.org/10.22159/ajpcr.2018.v11i11.26343

\section{INTRODUCTION}

In the human body, skin is the biggest organ that represents around one-tenth of the body mass. Overall, it serves as a shielding barrier against chemical, mechanical, microbial invasion, osmotic, and photodamage [1]. Skin defects and necrosis can affect from burns, soft tissue trauma, UV radiation, and chemical-contact [2]. Skin regeneration holds a place of essential value in tissue regeneration research. Conventional therapies employed to repair skin defects such as autograft, allograft, and xenograft $[3,4]$. Although autografts are commonly used to repair skin defects, there are limitations of donor sites [5]. Alternatively, allografts can be gained in wealth, though these are often related to high risk of immune refusal and disease transmission. To resolve these problems pertaining to predictable treatments, tissue-engineered skin substitutes are used nowadays. Major limitations of these tissue-engineered skin substitutes are their high cost and low mechanical strength.

Tissue engineering, a term was equivalent with regenerative medicine, provides an alternative to replacement of tissues, by increasing substitutes that restore, retain, recover, and improve tissue function. Tissue engineering strategies consist of three major elements: Cells, signaling molecules, and natural or artificial scaffolds. Such scaffolds have been prepared for use in different tissues such as bone [6-8], cartilage [8], muscle [9], and skin [10]. Scaffolds for use in regenerative medicine offer the support for the repopulation and specialization of stem cells, blood vessels, and extracellular matrices [11].

Divergent materials such as biopolymers and synthetic materials were used in the tissue engineering purpose [12]. Biopolymers have greater bioactive properties over synthetic polymeric scaffolds. However, synthetic polymers can discharge acidic degradation products and raise serious immune reactions in the body and poisonous to the host tissues $[13,14]$. Biopolymers have chemical compositions similar to that of the host biological system and serve as a tissue contact or even can bind with the host tissue $[15,16]$. Biopolymers normally possess vastly controlled structures and may contain extracellular matrix (ECM) ligands, which can bind to cell receptors. In addition, the biopolymeric material based scaffolds can conduct cells to grow at different phases of development [17-19].

\section{COLLAGEN}

Collagen, an extracellular protein abundant in animal tissues and made up of specific amino acids - glycine, proline, hydroxyproline and arginine, and collagen makes up around $30 \%$ of the proteins within the body. These are hard and tough structures found in bones, tendons, and ligaments. Collagen has huge importance in tissue engineering because of its biological nature, outstanding biodegradability and biocompatibility [20]. Collagen provides strength to different structures of the body and also protects structures such as the skin by preventing absorption and scattering of pathogenic substances, environmental toxins, microorganisms, and cancerous cells. Collagen is regarded as an ultimate scaffold or matrix for tissue engineering, and it is the main protein component of the ECM, provided that support to connective tissues such as skin, tendons, bones, cartilage, blood vessels, and ligaments [21-25]. This uniqueness has also contributed to the safe use of collagen in biomedical applications $[26,27]$.

Although it has been one of the favorite biomaterials for in vivo medical applications and difficult processing, low mechanical properties have been the barriers to its broad use in biomedical and engineering applications. To enhance the poor mechanical properties strengthening with fillers or cross-linking has been used, while the existence of residual cross-linking agents leads to lethal side effects [28]. Among the various types of collagen, type I collagen has been comprehensively used as a tissue engineering scaffold and wound dressing system due to its low antigenic and high direct cell adhesion properties. At present, the main sources of type I collagen are bovine or porcine dermis [29].

Due to bovine spongiform encephalopathy, transmissible spongiform encephalopathy, and foot and mouth disease in pigs and cattle, the use of collagen and its derivative products from these sources has been restricted [30]. Type I collagen has also been extracted from skin, bone pins, and scales of freshwater and marine fish, chicken skin, and other oceanic animals such as squid, octopus, and starfish [21-25]. Collagen 
from these sources has been evaluated for their prospective application as a substitute for mammalian collagen [31]

\section{CHITIN}

Chitin is a natural polysaccharide found mainly in the shell of crustacean, cuticles of insects and cell walls of fungi. It is the second richest polymerized carbon available in natural ants, as well as the second highly abundant natural biopolymer after collagen. It has been widely exploited due to its ECM-mimicking character and one of the degradation products, namely $\mathrm{N}$-acetyl-D-glucosamine and reported supporting fibroblast proliferation and structured collagen deposition (Fig. 1) [32]. Chitin also promotes macrophage movement and stimulates the deposition of granulation tissue and also has revealed a function in vascularization and good hemostatic action [33]. Optimal biomedical design focuses on the use of bioinert materials to minimize inflammatory response alleviated by unknown body reactions, thus, chitin, being bioactive and bioinert would be a proper candidate. Chitin, due to its less quantity of 2-amino-2-deoxy-D-glucose, is less soluble in acidic solvents, deficient in the property of protonation [34]. The abundant hydroxyl group and the $\mathrm{N}$-acetyl group that are associated with inter- and intra-molecular hydrogen bonding explain the high crystallinity of such aggregates.

Use of chitin in wound healing dressings arises from the ability of $\mathrm{N}$-acetyl-glucosamine to speed up the rate of tissue repair, and to avoid the development of scars and reduction of the skin [35]. It is invoked as a powder in the beginning, at present it is being incorporated into a variety of materials such as films and membranes, gels, and woven and non-woven dressings [36]. The high crystallinity of chitin compromises the mechanical integrity of such scaffolds. The latter was found to be particularly suited to the treatment of burns, cutaneous lesions, and ulcers, and skin grafts for their high-quality of absorbance, adhesive character, and permeability to oxygen [36-38].

\section{CHITOSAN (CHN)}

CHN is a biopolymer fully or partially deacetylated form of chitin and consisting of glucosamine and N-acetyl-D-glucosamine (Fig. 2) and has been extensively exploited for biomedical and tissue engineering applications (skin, bone, cartilage, and vascular grafts to substrates for mammalian cell culture) due to its affirmative properties such as non-toxic, renewable, biocompatibility, biodegradability, nonantigenic, and bioactiveness [39-41]. The gelation of CHN takes place at body temperature and CHN having the ability to interact with growth factors and hold proteins, makes it a significant material for tissue engineering $[42,43]$

The degradation of CHN is limited by the remaining amount of acetyl component, and it quickly degrades in vivo conditions. All these favorable characteristics made CHN an attractive material for tissue engineering [40]. However, in CHN scaffolds, the porosity can be restricted which affects the strength and elasticity of the tissue engineering scaffold [44].

The cationic nature of $\mathrm{CHN}$ enables it to interact with negatively charged polymers such as HYA to form a polyelectrolyte complex (PEC) through ionic bonding. The HYA and CHN are prone to swelling individually and therefore do not produce stable scaffolds. However, the formation of PEC causes the construction of constant and dynamic scaffolds [45]. Thus, formed scaffolds will improve the properties of the individual polymers such as increased stability, superior cell attachment, and enhanced mechanical property [42].

\section{ALGINATE}

Alginate is a naturally occurring anionic and hydrophilic polysaccharide. It is one of the most abundant biosynthesized materials, and watersoluble biopolymer is extracted from brown seaweed and bacteria [43]. Alginate contains blocks of (1-4)-linked $\beta$-D-mannuronic acid (M) and
$\alpha$-L-guluronic acid (G) monomers (Fig. 3). Naturally, the blocks are composed of three different forms of polymer segments: Successive G residues, successive $M$ residues, and alternating MG residues.

Alginate is of particular interest for a wide variety of applications as a biomaterial and particularly as the sustaining matrix or delivery system for tissue repair and regeneration. Due to its wonderful properties in terms of biocompatibility, biodegradability, nonantigenicity, and chelation ability, alginate has been extensively used in a variety of biomedical applications including tissue engineering, drug delivery and in some formulations preventing gastric reflux [44]. The result of naturally available polysaccharides, alginate exhibits a pHdependent anionic nature and has the capability to react with cationic polyelectrolytes and proteoglycans. Therefore, delivery systems for cationic drugs and molecules can be obtained through easy electrostatic interactions [46].

Alginate has been used in a number of wound dressings [47]. Alginatebased wound dressings such as sponges, hydrogels, and electrospun mats are promising substrates for wound healing that suggests many reward including hemostatic capability and gel-forming ability on absorption of wound exudates $[48,49]$. Alginate has found to acquire numerous significant elements attractive in a wound dressing such as good water absorptive, conformability, optimal water vapor transmission rate, and gentle antiseptic properties coupled with

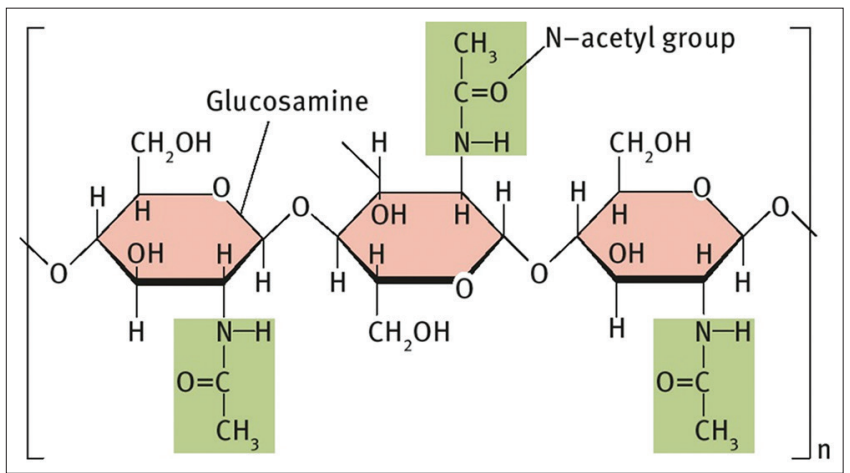

Fig. 1: Structure of chitin

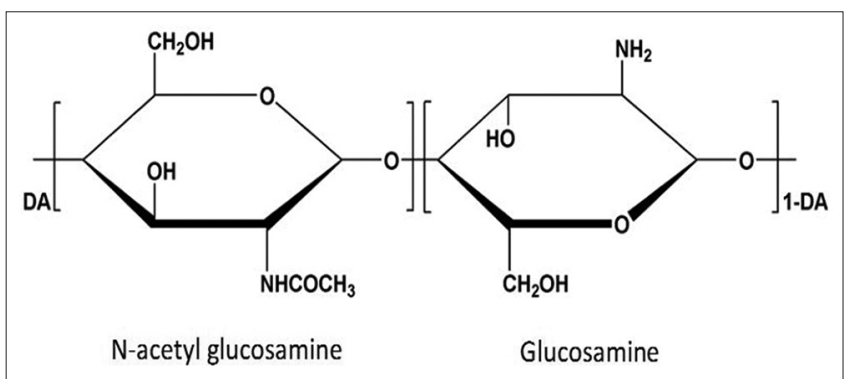

Fig. 2: Structure of chitosan

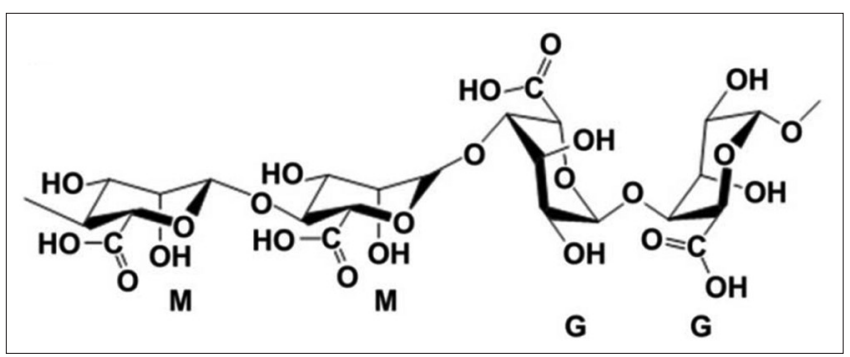

Fig. 3: Structure of alginate 
nontoxicity and biodegradability. Balakrishnan et al. showed that an informing hydrogel wound dressing prepared from gelatin and oxidized alginate in the presence of small concentrations of borax [28]. The composite matrix has the hemostatic effect of gelatin; the wound healing promotes the feature of alginate and the antiseptic property of borax to make it a possible wound dressing material. Moreover, since the structure lacks a signal sequence for cell adhesion, alginate-based dressings are well known for wound management and keep away from secondary injury when peeling off. In particular, wound dressings of alginate-based sponge are universally used to treat the wound with large volume exudation [28,48,49].

As a U.S. Food and Drug Administration approved polymer, alginate has become one of the most essential biomaterials for various applications in regeneration medicine, nutrition supplements, semi-permeable separation, etc. [45-47].

\section{GELLAN}

Gellan gum is a linear anionic polysaccharide composed of repeating units of glucose, glucuronic acid, and rhamnose [50,51]. It exists in the acetylated form, which is the initial raw material, and the deacetylated form, which is the most frequently used [52,53]. Gellan gum is noncytotoxic and can be simply processed without the use of insensitive reagents into transparent gels that are resistant to heat and acid stress [54]. Gellan gum gels are frequently utilized in the food industry as thickening agents or stabilizers. In the biomedical field, most applications are recommended for drug delivery approaches [55].

\section{GELATIN}

Gelatin is a derivative of collagen and usually obtained by the controlled hydrolysis of collagen extracted from animal tissues, such as skin and bovine and porcine bone. Gelatin is better-quality in its biological properties, ease of processing into microspheres, gentle gelling performance, controllable degradation through the optimization of cross-linking and the presence of the great quantity of functional groups that can be further derivatized and modified [56].

The electrostatic nature of collagen is hardly modified through the acid process because of a less invasive reaction to amide groups of collagen. As a result, the isoelectric point of gelatin that is obtained with the acid process will remain similar to that of collagen [57]. Using gelatin carriers for cell delivery as showed to become also a promising technology for tissue engineering applications. Several examples include bovine and human chondrocytes [58], mesenchyme stem cells [59], and human preadipocytes [60]. The strategies range from the coimplantation of loaded microspheres [60] to the incorporation of cells into porous scaffolds [61] and, in general, the in vivo results show the higher effectiveness of using gelatin carriers-based technology. Gelatin is generally applied in the pharmaceuticals industry for drug delivery, with many orally delivered capsules being based on gelatin. Gelatin and other natural polymers have been studied in vivo and in vitro for their potential in pulmonary drug delivery and sustained release [62].



Fig. 4: Structure of curcumin

\section{CURCUMIN}

Curcumin (diferuloylmethane) (1,7-bis (4-hydroxy-3-methoxyphenyl)-1, 6-heptadiene-3, 5-dione) (Fig. 4), is a naturally occurring multifunctional polyphenolic phytoconstituent, an Orange-yellow pigment obtained from the rhizomes of Curcuma longa Linn. (Zingiberaceae) [63].

Turmeric contains protein (6.3\%), fat (5.1\%), minerals (3.5\%), carbohydrates $(69.4 \%)$, and moisture $(13.1 \%)$. The essential oil $(5.8 \%)$ obtained by steam distillation of rhizomes has a-phellandrene $(1 \%)$, sabinene $(0.6 \%)$, cineol $(1 \%)$, borneol $(0.5 \%)$, zingiberene $(25 \%)$, and sesquiterpenes (53\%). Curcumin possesses a number of biological activities including anticancer, anti-inflammatory [64,65] and antioxidant, antimicrobial, antiviral [66], and wound healing activities and suppresses proliferation of a wide variety of tumor cells [67]. Topical applications of curcumin provide antibacterial, anti-inflammatory, and antioxidant (free radical scavenging) activity and patients wound healing has greatly improved [68]. The curcumin loaded CFNGO has appreciable mechanical strength (when $2 \%$ of NGO was combined with $1 \%$ of collagen), cell adherence and proliferation, biocompatibility, etc. [69].

\section{CONCLUSION}

Skin tissue engineering aims to restore, repair the diseased or damaged tissue. Polymeric biomaterials have several important uses in addition to skin tissue engineering. The bio uniqueness categorizes the natural-origin polymers as one of the most eyecatching options to be used in the tissue engineering field and drug delivery applications.

\section{AUTHOR'S CONTRIBUTIONS}

Concept and collection of data - Gowrisankar L, Usha P. Writing the article and critical review of article - Gowrisankar L, Ganesh Murali J. Final approval of the article - Gowrisankar L.

\section{CONFLICTS OF INTEREST}

Nil.

\section{REFERENCES}

1. Chong EJ, Phan TT, Lim IJ, Zhang YZ, Bay BH, Lim CT, et al. Evaluation of electrospun PCL/gelatin nanofibrous scaffold for wound healing and layered dermal reconstitution. Acta Biomater 2007;3:321-30.

2. Bottcher-Haberzeth S, Biedermann T, Reichmann E. Tissue engineering of skin. Burn 2010;36:450-60.

3. Murugan R, Huang ZM, Yang F, Ramakrishna S. Nanofibrous scaffold engineering using electrospinning. Nanosci Nanotechnol 2007;7:4595-3.

4. Kumbar SG, Nukavarapu SP, James R, Nair LS, Laurencin CT. Electrospun poly (lactic acid-co-glycolic acid) scaffolds for skin tissue engineering. Biomaterials 2008;29:4100-7.

5. Gupta SK, Dinda AK, Potdar PD, Mishra NC. Fabrication and characterization of PCL/gelatin/chitosan ternary nanofibrous composite scaffold for tissue engineering applications. Mater Sci Eng C 2013;33:4032-8

6. Miyaji H, Sugaya T, Ibe K, Ishizuka R, Tokunaga K, Kawanami M. Root surface conditioning with bone morphogenetic protein-2 facilitates cementum-like tissue deposition in beagle dogs. J Periodont Res 2010;45:58

7. Shimoji S, Miyaji H, Sugaya T, Tsuji H, Hongo T, Nakatsuka M, et al. Bone perforation and placement of collagen sponge facilitate bone augmentation. J Periodont 2009;80:5

8. Hutmacher DW. Scaffolds in tissue engineering bone and cartilage. Biomaterials 2000;21:2529.

9. McKeon-Fischer KD, Flagg DH, Freeman JW. Coaxial electrospun poly(e-caprolactone), multiwalled carbon nanotubes, and polyacrylic acid/polyvinyl alcohol scaffold for skeletal muscle tissue engineering. J Biomed Mater Res A 2011;99:493.

10. Ma L, Gao C, Mao Z, Zhou J, Shen J, Hu X, et al. Collagen/chitosan porous scaffolds with improved biostability for skin tissue engineering. Biomaterials 2003;24:4833.

11. Chen F, Jin Y. Periodontal tissue engineering and regeneration: 
Current approaches and expanding opportunities. Tissue Eng Part B 2010;16:219.

12. Liao JF, Qu Y, Chu BY, Zhang XN, Qian ZY. Biodegradable CSMA/ $\mathrm{PECA} /$ grapheme porous hybrid scaffold for cartilage tissue engineering. Sci Rep UK 2015;5:9879.

13. Chen GP, Ushida T, Tateishi T. A biodegradable hybrid sponge nested with collagen microsponges. J Biomed Mater Res 2000;51:273-9.

14. Lahiji A, Sohrabi A, Hungerford DS, Frondoza CG. Chitosan supports the expression of extracellular matrix proteins in human osteoblasts and chondrocytes. J Biomed Mater Res 2000;51:586-95.

15. Jaikumar D, Sajesh KM, Soumya S, Nimal TR, Chennazhi KP, Nair SV, et al. Injectable alginate-O-carboxymethyl chitosan/nano fibrin composite hydrogels for adipose tissue engineering. Int J Biol Macromol 2015;74:318-26.

16. Unnithan AR, Sasikala AR, Murugesan P, Gurusamy M, Wu DM, Park $\mathrm{CH}$, et al. Electrospun polyurethane-dextran nanofiber mats loaded with estradiol for post-menopausal wound dressing. Int J Biol Macromol 2015;77:1-8.

17. Kavya KC, Jayakumar R, Nair S, Chennazhi KP. Fabrication and characterization of chitosan/gelatin $/ \mathrm{nSiO} 2$ composite scaffold for bone tissue engineering. Int J Biol Macromol 2013;59:255-63.

18. Burg KJL, Porter S, Kellam JF. Biomaterial developments for bone tissue engineering. Biomaterials 2000;21:2347-59.

19. Kim J, Kim IS, Cho TH, Lee KB, Hwang SJ, Tae G, et al. Bone regeneration using hyaluronic acid-based hydrogel with bone morphogenic protein-2 and human mesenchymal stem cells. Biomaterials 2007;28:1830-37.

20. Barnes CP, Sell SA, Boland ED, Simpson DG, Bowlin GL. Nanofiber technology: Designing the next generation of tissue engineering scaffolds. Adv Drug Delivery Rev 2007;59:1413-33.

21. Hutmacher DW, Goh JC, Teoh SH. An introduction to biodegradable materials for tissue engineering applications. Ann Acad Med Singapore 2001;30:183-91.

22. Park SN, Park JC, Kim HO, Song MJ, Suh H. Characterization of porous collagen/hyaluronic acid scaffold modified by 1-ethyl-3(3-dimethylaminopropyl) carbodiimide cross-linking. Biomaterials 2002;23:1205-12.

23. Eyre DR. Collagen: Molecular diversity in the body's protein scaffold. Science 1980;207:1315-22.

24. Kemp PD. Tissue engineering and cell-populated collagen matrices. Methods Mol Biol 2000;139:287-93.

25. Lee $\mathrm{CH}$, Singla A, Lee Y. Biomedical applications of collagen. Int J Pharmacogn 2001;221:1-22.

26. Desimone MF, Helary C, Giraud-Guille MM, Livage J, Coradin T. Fibroblast encapsulation in hybrid silica-collagen hydrogels. Mater J Chem 2009;20:666-8.

27. Xia Z, Yu X, Jiang X, Brody HD, Rowe DW, Wei M. Fabrication and characterization of biomimetic collagen-apatite scaffolds with tunable structures for bone tissue engineering. Acta Biomater 2013;9:7308-19.

28. Balakrishnan B, Mohanty M, Umashankar PR, Jayakrishnan A. Evaluation of an in situ forming hydrogel wound dressing based on oxidized alginate and gelatin. Biomaterials 2005;26:6335-42.

29. Ogawa M, Moody MW, Portier RJ, Bell J, Schexnayder MA, Losso JN. Biochemical properties of black drum and sheepshead sea bream skin collagen. J Agric Food Chem 2003;51:8088-92

30. Jongjareonrak A, Benjakul S, Visessanguan W, Nagai T, Tanaka M. Isolation and characterisation of acid and pepsin-solubilised collagens from the skin of brownstripe red snapper. Food Chem 2005;93:475-84.

31. Wong Po Foo C, Kaplan DL. Genetic engineering of fibrous proteins: Spider dragline silk and collagen. Adv Drug Deliv Rev 2002;54:1131-43.

32. Anisha BS, Deepthi S, Annapoorna M, Chennazhi KP, Nair SV, Jayakumar R. Chitosan-hyaluronic acid/nano chondroitin sulphateternary composite sponges for biomedical use. Carbohydr Polym 2013;92:1470-6.

33. Yang TL. Chitin-based materials in tissue engineering: Applications in soft tissue and epithelial organ. Int J Mol Sci 2011;12:1936-63.

34. Anitha A, Sowmya S, Sudheeshkumar PT, Deepthi S, Chennazhi KP, Ehrlich H, et al. Chitin and chitosan in selected biomedical applications. Prog Polym Sci 2014;39:1644-67.

35. Dai T, Tanaka M, Huang, YY, Hamblin MR. Chitosan preparations for wounds and burns: Antimicrobial and wound-healing effects. Expert Rev Anti Infect Ther 2011;9:857-79.

36. Shalumon KT, Binulal NS, Selvamurugan N, Nair SV, Menon D, Furuike T, et al. Electrospinning of carboxymethyl chitin/poly (vinyl alcohol) nanofibrous scaffolds for tissue engineering applications. Carbohydr Polym 2009;77:863-9.

37. Granville-Chapman J, Jacobs N, Midwinter MJ. Pre-hospital hemostatic dressings: A systematic review. Injury 2011;42:447-59.
38. Jayakumar R, Prabaharan M, Sudheesh Kumar PT, Nair SV, Tamura H. Biomaterials based on chitin and chitosan in wound dressing applications. Biotechnol Adv 2011;29:322-37.

39. Nettles DL, Elder SH, Gilbert JA. Potential use of chitosan as a cell scaffold material for cartilage tissue engineering. Tissue Eng 2002;8:1009-16.

40. De Azevedo EP. Chitosan hydrogels for drug delivery and tissue engineering applications. Int J Pharm Pharm Sci 2015;7:8-14.

41. Nikpour MR, Rabiee SM, Jahanshahi M. Synthesis and characterization of hydroxyapatite/chitosan nanocomposite materials for medical engineering applications. Compos Part B Eng 2012;43:1881-6.

42. Mohandas A, Anisha BS, Chennazhi KP, Jayakumar R. Chitosanhyaluronic acid/VEGF loaded fibrin nanoparticles composite sponges for enhancing angiogenesis in wounds. Colloids Surf B 2015;127:105-13.

43. Indrani DJ, Budiyanto E, Hayun H. Preparation and characterization of porous hydroxyapatite and alginate composite scaffolds for bone tissue engineering. Int J Applied Pharm 2017;9:98-2.

44. Cheung HY, Lau KT, Lu TP, Hui D. A critical review on polymer-based bioengineered materials for scaffold development. Compos Part B Eng 2007;38:291.

45. Bouhadir KH, Lee KY, Alsberg E, Damm KL, Anderson KW, Mooney DJ. Degradation of partially oxidized alginate and its potential application for tissue engineering. Biotechnol Prog 2001;17:945-50.

46. Teo SY, Lee SY, Rathbone MJ, Gan SN. Polymeric materials as platforms for topical drug delivery: A review. Int J Pharm Pharm Sci 2017;9:14-20

47. Rowley JA, Madlambayan G, Mooney DJ. Alginate hydrogels as synthetic extracellular matrix materials. Biomaterials 1999;20:45-53.

48. Li X, Chen S, Zhang B, Li M, Diao K, Zhang Z, et al. In situ injectable nano-composite hydrogel composed of curcumin, N,O-carboxymethyl chitosan and oxidized alginate for wound healing application. Int $\mathrm{J}$ Pharm 2012;437:110-9.

49. Hooper SJ, Percival SL, Hill KE, Thomas DW, Hayes AJ, Williams DW. The visualisation and speed of kill of wound isolates on a silver alginate dressing. Int Wound J 2012;9:633-42.

50. Jansson PE, Lindberg B, Sandford PA. Structural studies of gellan gum, an extracellular polysaccharide elaborated by Pseudomonas elodea. Carbohydr Res 1983;124:35.

51. Moorhouse R, Colegrove GT, Sandford P, Baird K, Kang KS. A New Gel-forming Polysaccharide. Washington, DC: D.A. Brandt; 1981

52. Rozier A, Mazuel C, Grove J, Plazonnet B. A novel, ion-activated, in-situ gelling polymer for ophthalmic vehicles. Effect on bioavailability of timolol. Int J Pharm 1989;57:163.

53. Grasdalen H, Smidsrod O. Gelation of gellan gum. Carbohydr Polym 1987;7:371.

54. Oliveira JT, Martins L, Picciochi R, Malafaya PB, Sousa RA, Neves NM, et al. Gellan gum: A new biomaterial for cartilage tissue engineering applications. J Biomed Mater Res A 2009;5:852-63.

55. Coviello T, Dentini M, Rambone G, Desideri P, Carafa M, Murtas E, et al. A novel cocrosslinked polysaccharide: Studies for a controlled delivery matrix. J Control Release 1998;55:57.

56. Wang H, Leeuwenburgh SC, Li Y. The use of micro-and nanospheres as functional components for tissue regerneration. Tissue Eng 2012:18:24-39.

57. Young S, Wong M, Tabata Y, Mikos AG. Gelatin as a delivery vehicle for the controlled release of bioactive molecules. J Control Release 2005;109:256-74

58. Malda J, Kreijveld E, Temenoff JS, Blitterswijk CA, Riesle J. Expansion of human nasal chondrocytes on macroporous microcarriers enhances redifferentiation. Biomaterials 2003;24:153-61.

59. Payne RG, McGonigle JS, Yaszemski MJ, Yasko AW, Mikos AG. Development of an injectable, in situ crosslinkable, degradable polymeric carrier for osteogenic cell populations. Part 2. Viability of encapsulated marrow stromal osteoblasts cultured on crosslinking poly (propylenefumarate). Biomaterials 2002;23:4373-80.

60. Kimura Y, Ozeki M, Inamoto T, Tabata Y. Adipose tissue engineering based on human preadip ocytes combined with gelatin microspheres containing basic fibroblast growth factor. Biomaterials 2003;24:2513-21.

61. Ponticiello MS, Schinagl RM, Kadiyala S, Barry FB. Gelatin-based resorbable sponge as a carrier matrix for human mesenchymal stem cells in cartilage regeneration therapy. J Biomed Mater Res 2000;52:246-55.

62. Sheth P, Myrdal PB. Polymers for pulmonary drug delivery. Controll Pulm Drug Deliv 2011;265-82.

63. Ammon HP, Wahl MA. Pharmacology of Curcuma longa. Planta Med 1991;57:1-7

64. Ruby AJ, Kuttan G, Babu KD, Rajasekharan KN, Kuttan R. Antitumour and antioxidant activity of natural curcuminoids. Cancer Lett 1995;94:79-83. 
65. Vasanthkumar T, Manjunatha H, Rajesh KP. Anti-inflammatory activity of curcumin and capsaicin augmented in combination. Int J Pharm Pharm Sci 2017;9:145-9.

66. Vajragupta O, Boonchoong P, Morris GM, Olson AJ. Active site binding modes of curcumin in HIV-1 protease and integrase. Bioorg Med Chem Lett 200;15:3364-8.

67. Panchatcharam M, Miriyala S, Gayathri VS, Suguna L. Curcumin improves wound healing by modulating collagen and decreasing reactive oxygen species. Mol Cell Biochem 2006;290:87-96.

68. Gopinath D, Ahmed MR, Gomathi K, Chitra K, Sehgal PK, Jayakumar R. Dermal wound healing processes with curcumin incorporated collagen films. Biomaterials 2004;25:1911-7.

69. Mitra T, Manna PJ, Raja ST, Gnanamanib AK, Undu PP. Curcumin loaded nano graphene oxide reinforced fish scale collagen-a 3D scaffold biomaterial for wound healing applications. RSC Adv 2015;5:98653-65. 